\title{
Hepato-toxic risk of gum arabic during adenine-induced renal toxicity prevention
}

\author{
Entsar A. Saad ${ }^{*}$, Hussam A. El-Gayar ${ }^{2}$, Reda S. EL-Demerdash ${ }^{2}$, Kholoud H. Radwan ${ }^{1,3}$ \\ ${ }^{1}$ Chemistry Department, Faculty of Science, Damietta University, Damietta, Egypt. \\ ${ }^{2}$ Urology and Nephrology Center, Faculty of Medicine, Mansoura University, Mansoura, Egypt. \\ ${ }^{3}$ Department of Biochemistry, Horus University in Egypt (HUE), Damietta, Egypt.
}

\begin{tabular}{l}
\hline ARTICLE INFO \\
\hline Received on: $20 / 03 / 2018$ \\
Accepted on: $26 / 08 / 2018$ \\
Available online: $30 / 12 / 2018$
\end{tabular}

\section{Key words:}

Antioxidants, gum arabic, liver damage, nephroprotective, renal failure.

\begin{abstract}
Objective: Lately, gum arabic (GA) is traditionally used in Middle East countries to ameliorate renal function of patients with chronic renal failure (CRF). This action is controversial and it is still experimentally under evaluation. We aimed to shed more light on the potential effects of GA administration to rats with adenine (AD)-induced CRF through investigating kidney and liver changes.

Material and Methods: Rats were divided into four groups treated for consecutive 28 days. Control group was given normal food and water. GA group was given GA ( $15 \% \mathrm{w} / \mathrm{v} /$ day $)$ in drinking water. AD group; received $\mathrm{AD}(50 \mathrm{mg} /$ $\mathrm{kg}$ /day, intraperitoneally). GA + AD group received both $\mathrm{AD}(50 \mathrm{mg} / \mathrm{kg} /$ day $)$ and $\mathrm{GA}(15 \% \mathrm{w} / \mathrm{v} /$ day $)$. On day 29 , rats were sacrificed and serum creatinine, urea, uric acid, blood urea nitrogen (BUN), aspartate aminotransferase (AST), alanine aminotransferase (ALT), albumin, bilirubin, cholesterol levels, and renal/hepatic malondialdehyde (MDA), superoxide dismutase (SOD), and catalase were estimated. Kidney/liver histo-pathological studies were performed.

Results: GA supplement efficiency in preventing AD-induced renal toxicity is clearly evident from histo-pathological examination and reduced urea, BUN, and creatinine levels. Also, it is proven that GA supplementation produces harmful effects on the liver as it increases ALT and AST levels.

Conclusion: Liver function tests should be monitored in chronic kidney disease (CKD) patients who utilize GA supplement.
\end{abstract}

\section{INTRODUCTION}

CKD is a real health problem worldwide (Saad et al., 2018; Umeukeje et al., 2018). Variable factors affect its onset and development like obesity, dyslipidemia, diabetes (Saad et al., 2015a; 2017a), cancer (Saad et al., 2017b; 2017c; 2017d), and exposure to toxicants (Saad, 2013; Toson et al., 2014). Also, inflammation and oxidative stress contribute to its pathogenesis and progression (Ali et al., 2013).

$\mathrm{CRF}$ is an irreversible loss of a great number of functional nephrons originated from an extensive diversity of disorders of glomeruli, tubules, renal interstitium, and blood vessels. It is manifested by structural and functional responses of remainder

\section{${ }^{*}$ Corresponding Author}

Entsar A. Saad, Chemistry Department, Faculty of Science, Damietta University,Damietta,Egypt.E-mail: entsarsaad@gmail.com nephrons that eventually result in glomerulo-sclerosis. Injured kidney has decreased size and broad casts in the urine sediment appear indicating dilated hypertrophied remaining nephrons. Inadequacy of functioning nephrons results in ineffective ride of body toxins, thereby uremic poisoning appears (El-Habibi, 2013). $\mathrm{AD}$-induced CRF model in animal results in complications similar to that produced in human CRF. Thus, this CRF model can be used experimentally for studying different complications related to a persistent uremic state (Ali et al., 2010).

Acacia gum (gum arabic, GA) is a water-soluble polysaccharide fiber produced from the dried gummy exudate of Acacia senegal (L.) Willd trees, stems, and branches, mostly in Sudan (about 80\%). It consists of D-galactose units backbone with branched chains of (1-3) linked $\beta$-D-galactopyranosyl units containing $\alpha$-L-arabinofuranosyl, $\alpha$-L-rhamnopyranosyl, $\beta$-Dglucuronopyranosyl, and 4-O-methyl- $\beta$-D-glucuronopyranosyl units, and contains high amounts of $\mathrm{Ca}^{2+}, \mathrm{K}^{+}$, and $\mathrm{Mg}^{2+}$ ions. It is 
edible and fermented to short chain fatty acids by colonic bacteria (Nasir, 2013).

GA has long been traditionally used as a pain-reliever base by Egyptians and to treat a wide diversity of diseases by Arabic physicians (Dobelis, 1986). It can offset diarrhea, exhibit anti-microbial activity, and promote teeth re-mineralization. Lately, it is traditionally used in the Middle East countries to ameliorate renal function of patients with CRF. This action of GA is controversial and it is still experimentally under evaluation (Nasir, 2013).

To our knowledge, GA is considered non-toxic when taken in food or medications; however, certain side effects may result, including cholesterol levels increase and allergic reactions in some people as well as uncoupling of oxidative phosphorylation in the heart and liver (Babiker et al., 2017). Until now, there are no enough investigations to find out all of the GA benefits/potential adverse effects, particularly during CRF treatment, the most common traditional use now among Arabs, especially Egyptians; therefore, more research concerning this issue is of interest. This will help to evaluate GA utilization as a supplement at the clinical level for patients with kidney disease and could help in how to avoid/control or prevent its undesirable effects if present aiming to maximize the benefit of its clinical use in such patients in the future.

The aim of this work was to investigate the hepatic and renal effects of GA administration to healthy rats and to rats with AD-induced CRF. Kidney and liver function changes were studied on both biochemical and histological levels, and oxidative stress state in both organs was also monitored.

\section{MATERIALS AND METHODS}

\section{Chemicals, kits, and plant material}

AD was obtained from Sigma Chemicals (St. Louis, MO), while AST and ALT kits were obtained from ELITech clinical systems, France. Albumin, cholesterol, total protein, and bilirubin kits were purchased from BIOMED, Cairo, Egypt. Creatinine, urea, and uric acid kits were purchased from Diamond Diagnostics, USA. MDA, SOD, and catalase were purchased from Biodiagnostic Company, Cairo, Egypt.

GA (Sudanese) was purchased from a Saudi Arabian local market, representing the type and source that were most commonly and traditionally used by Egyptians in particular. Dried gum was grounded into fine powder, kept in air tight plastic containers, and stored at $5^{\circ} \mathrm{C}$ until used. Voucher specimen will be kept at Herbarium of Botany Department, Faculty of Science, Damietta University, Egypt.

Gum extract $(15 \% \mathrm{w} / \mathrm{v}$, the most common traditionally used concentration) was made by soaking $15 \mathrm{~g}$ in $100 \mathrm{ml}$ of distilled water, settled for 24 hours and then filtered. It was prepared freshly for every use.

\section{Animals}

Adult male Sprague-Dawley rats (170-190 g) brought from Urology and Nephrology Centre, Mansoura University, Egypt were used. According to the National Institute of Health (1996), rats were housed for 10 days prior to experimental use in cages (four in each) under controlled conditions; temperature of $25^{\circ} \mathrm{C}$, relative humidity of $60 \%-70 \%$, and a $12 / 12$ hours light/dark cycle. Normal food and water ad libitum were allowed. Our study was approved by the Animal House of Biochemistry, Chemistry Department, Faculty of Science, Damietta University, Egypt.

\section{Experimental design}

Rats were gathered into four groups of 10 rats for each. AD group; injected intraperitoneally (ip) with AD (50 mg/kg/day) for 28 successive days. AD-induced CRF was confirmed via detection of serum creatinine and urea every week. GA + AD group; received GA $(15 \% \mathrm{w} / \mathrm{v})$ orally in drinking water daily concomitant with AD (50 mg/kg/day) injection for 28 successive days. GA group; received GA $(15 \% \mathrm{w} / \mathrm{v})$ orally in drinking water daily for successive 28 days. Normal control group; received only the respective vehicles.

\section{Biochemical analysis}

On day 29, all animals were fasted for 12 hours, then sacrificed under diethyl ether anesthesia and blood samples were collected, left to clot and the sera were separated and stored at $-20^{\circ} \mathrm{C}$ until used for estimation of AST, ALT, albumin, cholesterol, total protein, total bilirubin, creatinine, urea, uric acid, and BUN levels. MDA, SOD, and catalase levels were estimated in kidney/ liver tissue homogenate $(10 \%)$ according to kits instructions.

\section{Histo-pathological analysis}

Residual washed liver and kidney, obtained after decapitation, were fixed in $10 \%$ formalin, processed, embedded in paraffin wax, cut into $5-\mu \mathrm{m}$ thick sections, stained with hematoxylin and eosin (H\&E) dye and examined.

\section{Statistical analysis}

Results are introduced as mean $\pm \mathrm{SD}$. Student's $t$-test was used for statistical analysis between two groups. $p<0.05$ was considered as significant. InStat statistical software version 3.10 (GraphPad, USA) was used for statistical calculations.

\section{RESULTS}

\section{Body weight changes}

Table 1 illustrates that the healthy control rats normally continued to gain weight gradually. Final body weight showed a significant reduction by $25 \%$ following daily injection of $\mathrm{AD}$, while when $\mathrm{AD}$ injection was combined with oral administration of GA it showed significant regain; body weight loss changed from $-25 \%$ in $\mathrm{AD}$ group to $-3.5 \%$ in $\mathrm{GA}+\mathrm{AD}$ group. Moreover, administration of GA alone firstly reduced body weight during the first week, then rats' body weight started to increase from the third week and go on.

\section{Biochemical effects of $G A$ administration to healthy rats}

\section{Renal function}

When orally administered to healthy rats, GA nonsignificantly increased the concentrations of urea, BUN, and creatinine by $30 \%, 29 \%$, and $25 \%$, respectively, while nonsignificantly decreased uric acid concentration by $18 \%$ (Table 2 ). 


\section{Hepatic function}

Figure 1 shows that by GAadministration in drinking water, the concentration of total bilirubin was decreased by $23 \%(p<0.05)$, total protein by $13 \%(p<0.05)$, and albumin by $8 \%(p<0.05)$, while ALT activity was increased by $32 \%(p<0.01)$, AST activity by $54 \%$ $(p<0.001)$, and cholesterol level by $33 \%(p<0.001)$.

\section{Oxidative stress}

Table 3 shows that by GA administration, the concentration of MDA was significantly increased by $40 \%$ associated with significant elevation in SOD activity by $33 \%$ and a significant decrease in catalase activity by $10 \%$ in kidney tissues. Whereas, MDA was non-significantly increased in liver tissues by $20 \%$ associated with a significant decrease in SOD activity by $26 \%$ and a significant increase in catalase activity by $42 \%$.

\section{Biochemical effects of $G A$ co-administration to rats with AD-induced CRF}

\section{Renal function}

Table 2 shows that AD causes significant $(p<0.001)$ increase in the concentrations of urea by $326 \%$, BUN by $326 \%$, creatinine by $67 \%$, and uric acid by $95 \%$ compared with the control group. Co-administration of GA significantly $(p<0.001)$ reduced the concentrations of urea by $256 \%$, BUN by $270 \%$, creatinine by $21 \%$, and uric acid by $53 \%$ when compared with those of the AD group. Comparing AD + GA group with the control group, levels of urea, BUN, uric acid, and creatinine are still higher by $19 \%$, $15 \%, 27 \%$, and $38 \%$, respectively, than their corresponding values in the control group.

\section{Hepatic function}

Figure 1 shows that $\mathrm{AD}$ causes significant $(p<0.001)$ increases in the concentration of total bilirubin by $431 \%$, ALT by $126 \%$, AST by $154 \%$, and cholesterol by $45 \%$ associated with significant $(p<0.001)$ decreases in total protein by $25 \%$ and in albumin concentration by $45 \%$. Comparing $\mathrm{AD}$ group with $\mathrm{GA}+\mathrm{AD}$ group, GA significantly $(p<0.01-p<0.001)$ reduced the concentrations of total bilirubin by $25 \%$, ALT by $46 \%$, AST by $115 \%$, and cholesterol by $33 \%$, while the concentration of albumin was significantly $(p<0.01)$ increased by $24 \%$ and total protein was significantly $(p<0.05)$ increased by $11 \%$. Comparing GA + $\mathrm{AD}$ group with the control group, these parameters were improved but still away from the values in the control group.

\section{Oxidative stress}

Table 3 shows that $\mathrm{AD}$ causes significant $(p<0.001)$ increase in the concentration of MDA in kidney by $70 \%$ and in liver tissues by $201 \%$, while it causes significant $(p<0.001)$ decreases in the SOD activity by $35 \%$ in kidney and by $67 \%$ in liver and in catalase activity in kidney by $28 \%$ and in liver by $22 \%$. Comparing $\mathrm{AD}$ group with $\mathrm{GA}+\mathrm{AD}$ group, GA significantly $(p<0.001)$ reduced the concentration of MDA in kidney by $52 \%$ and in liver by $73 \%$, while SOD activity in kidney was significantly increased by $123 \%(p<0.001)$ and in liver by $178 \%(p<0.001)$. Also, the catalase activity in kidney was significantly increased by $57 \%(p<0.001)$ and in liver by $98 \%(p<0.001)$.

\section{Histo-pathological changes}

Administration of GA to normal rats did not cause any harm to renal/hepatic tissues normal architecture, while AD injection caused congestion and necrosis of renal glomeruli with necrosis of renal tubular epithelium lining renal tubules besides lymphohistiocytic infiltration in hepatic tissue with coagulative necrosis of hepatocytes. In $\mathrm{GA}+\mathrm{AD}$ group, little improvements in renal and hepatic tissues had been observed (Figures 2 and 3; Table 4).

\section{DISCUSSION}

Comparing to healthy control, GA administration to healthy rats for consecutive 4 weeks reduced body weight during

Table 1. Body weight ( $\mathrm{g}$ ) changes of rats in different groups throughout the experimental period.

\begin{tabular}{|c|c|c|c|c|c|}
\hline Groups & Day 0 & First week & Second week & Third week & Fourth week \\
\hline Control & $178.1 \pm 7.8$ & $186.60 \pm 8.26$ & $192.20 \pm 6.77$ & $209.40 \pm 8.56$ & $221.60 \pm 8.28$ \\
\hline$\%$ Change from day 0 & $0.0 \%$ & $+4.77 \%$ & $+7.9 \%$ & $+17.57 \%$ & $+24.42 \%$ \\
\hline AD & $203.3 \pm 9.2$ & $190.62 \pm 6.54$ & $186.13 \pm 6.51$ & $163.50 \pm 4.9^{\$ \$ s}$ & $153.6 \pm 5.441^{\mathrm{sss}}$ \\
\hline$\%$ Change from day 0 & $0.0 \%$ & $-6.24 \%$ & $-8.45 \%$ & $-19.58 \%$ & $-24.45 \%$ \\
\hline GA & $189.9 \pm 4.45$ & $186.40 \pm 3.80$ & $183.60 \pm 4.14$ & $186.20 \pm 3.08^{s s s}$ & $191.40 \pm 3.58^{s s s}$ \\
\hline$\%$ Change from day 0 & $0.0 \%$ & $-1.84 \%$ & $-3.32 \%$ & $-1.95 \%$ & $+0.79 \%$ \\
\hline $\mathbf{G A}+\mathbf{A D}$ & $208.5 \pm 3.17$ & $198.60 \pm 2.11^{\$ \$ \$, *}$ & $190.80 \pm 2.97^{\$ \$ \$, *}$ & $194.50 \pm 3.62^{\$ \$ \$, * * *}$ & $201.20 \pm 5.26^{\$ \$ \$, * * *}$ \\
\hline$\%$ Change from day 0 & $0.0 \%$ & $-4.75 \%$ & $-8.49 \%$ & $-6.71 \%$ & $-3.5 \%$ \\
\hline
\end{tabular}

$\mathrm{AD}=$ adenine, $\mathrm{GA}=$ gum arabic. Data are expressed as mean $\pm \mathrm{SD}(n=10$ rats in each group $) .{ }^{\$ \$} p<0.001$ versus control group. $*$ and $* * * p<0.05$ and $p<0.001$, respectively, versus AD group.

Table 2. Urea, blood urea nitrogen (BUN), creatinine, and uric acid levels in different groups.

\begin{tabular}{|c|c|c|c|c|}
\hline Groups & Urea (mg/dl) & Creatinine (mg/dl) & BUN (mg/dl) & Uric acid (mg/dl) \\
\hline Control & $26.63 \pm 2.21$ & $0.63 \pm 0.08$ & $12.42 \pm 1.04$ & $2.14 \pm 0.40$ \\
\hline AD & $113.3 \pm 12.7^{\$ \$ \$}$ & $1.05 \pm 0.107^{\$ \$ \$}$ & $52.93 \pm 5.95^{5 \$ \$}$ & $4.17 \pm 0.46^{\$ \$ \$}$ \\
\hline GA & $34.51 \pm 4.32$ & $0.73 \pm 0.13$ & $16.05 \pm 2.01$ & $1.75 \pm 0.32$ \\
\hline $\mathbf{G A}+\mathbf{A D}$ & $31.8 \pm 5.37^{* * * *}$ & $0.87 \pm 0.105^{\$ \$ \$, * * *}$ & $14.32 \pm 2.52^{* * *}$ & $2.72 \pm 0.56^{* * * *}$ \\
\hline
\end{tabular}

$\mathrm{AD}=$ adenine, $\mathrm{GA}=$ gum arabic. Data are expressed as mean $\pm \mathrm{SD}(n=10$ rats in each group $) .{ }^{\$ \$ \$} p<0.001$ versus control group. ${ }^{* * *} p<0.001$ versus $\mathrm{AD}$ group. 

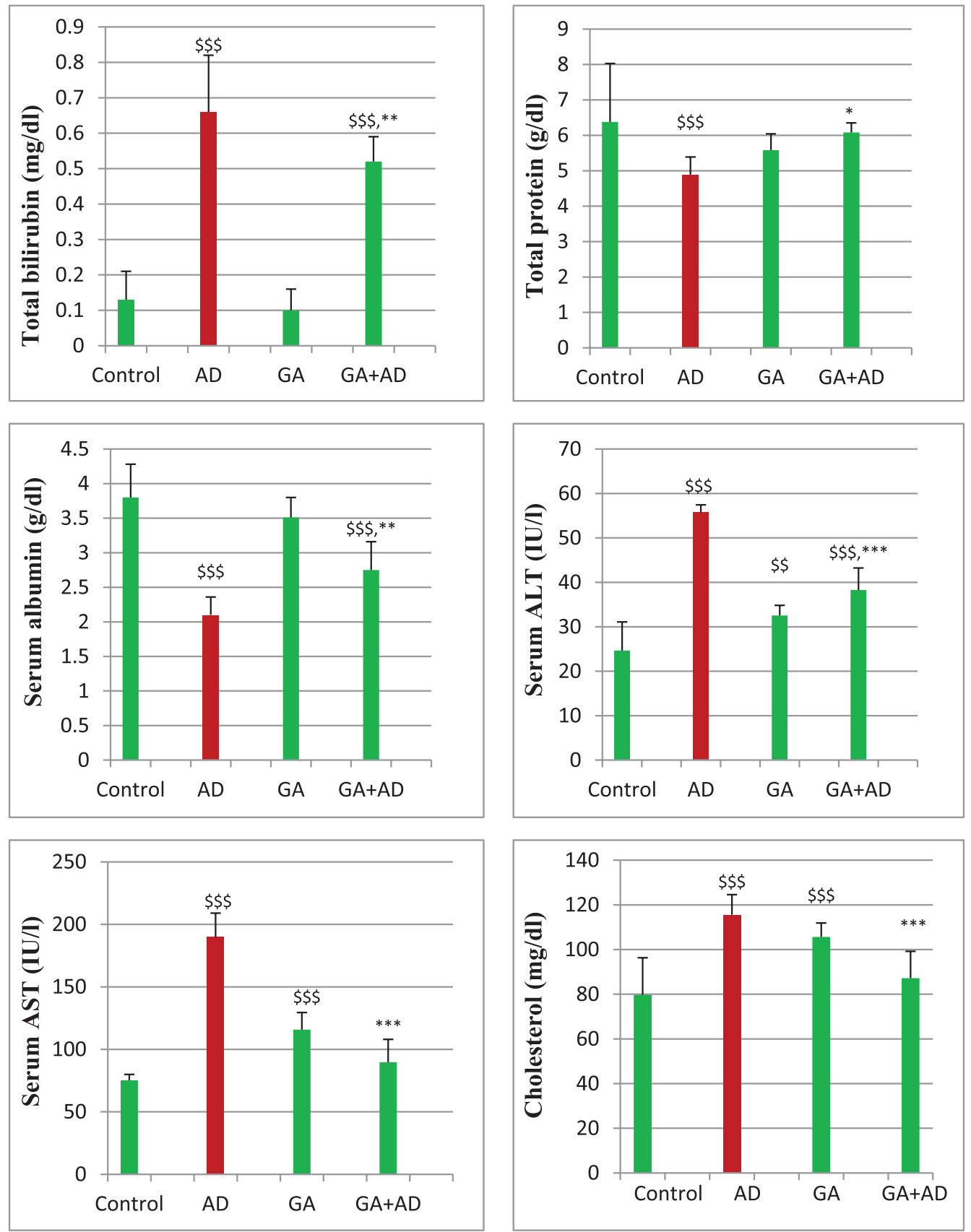

Figure 1. Bilirubin, protein, albumin, alanine aminotransferase (ALT), aspartate aminotransferase (AST), and cholesterol levels in different groups. Each column represents the mean $\pm \mathrm{SD}(n=10$ rats in each group). $\$ \$$ and $\$ \$ \$: p<0.01$ and $p<0.001$, respectively, versus control group. ${ }^{*},{ }^{*}$ and ${ }^{* * *}: p<0.05, p<0.01$ and $p<0.001$, respectively, versus $\mathrm{AD}$ group.

Table 3. Malondialdehyde (MDA), superoxide dismutase (SOD), and catalase levels in kidney and liver tissues.

\begin{tabular}{|c|c|c|c|c|c|c|}
\hline \multirow{2}{*}{ Groups } & \multicolumn{2}{|c|}{ MDA (nmol/g tissue) } & \multicolumn{2}{|c|}{ SOD (U/g tissue) } & \multicolumn{2}{|c|}{ Catalase (K Unit/g tissue) } \\
\hline & kidney & Liver & Kidney & Liver & Kidney & Liver \\
\hline Control & $215.34 \pm 54.72$ & $148.60 \pm 38.57$ & $1468.40 \pm 390.19$ & $1877.98 \pm 74.36$ & $2.73 \pm 0.11$ & $1.65 \pm 0.08$ \\
\hline AD & $366.86 \pm 31.03^{\$ \$ \$}$ & $447.04 \pm 86.34^{\$ \$ \$}$ & $952.25 \pm 181.71^{\$ \$ \$}$ & $613.74 \pm 187.52^{\$ \$ s}$ & $1.595 \pm 0.19^{\$ \$ \$}$ & $1.29 \pm 0.04$ \\
\hline GA & $301.20 \pm 14.53^{\mathrm{sss}}$ & $186.18 \pm 58.96$ & $1948.20 \pm 55.15^{\text {s\$s }}$ & $1381.93 \pm 89.57^{\$ \$ s}$ & $2.47 \pm 0.10^{s s}$ & $2.34 \pm 0.6^{\$ \$ \$}$ \\
\hline $\mathbf{G A}+\mathbf{A D}$ & $177.13 \pm 60.77^{* * * *}$ & $121.20 \pm 13.70^{* * * *}$ & $2126.05 \pm 345.85^{\$ \$ \$, * * *}$ & $1703.44 \pm 171.32^{* * *}$ & $2.51 \pm 0.16^{S, * * *}$ & $2.55 \pm 0.299^{\$ \$ \$, * * *}$ \\
\hline
\end{tabular}

$\mathrm{AD}=$ adenine, $\mathrm{GA}=$ gum arabic. Data are expressed as mean $\pm \mathrm{SD}(n=10$ rats in each group $) . \$, \$ \$, \$ \$ s p<0.05, p<0.01$, and $p<0.001$, respectively, versus control group. $* * * p<0.001$ versus AD group. 
the first week, then rats' body weight started to increase, with a rate lower than that in the control group, from the third week and go on. This may be due to GA ability to slow intestinal glucose transport as previously reported by Nasir (2013). In addition, it did not significantly change levels of bilirubin, protein, and albumin; however, they were slightly decreased, while it significantly $(p<0.01-p<0.001)$ increased ALT activity by $32 \%$ and AST activity by $54 \%$. Observed elevation in liver enzymes may be related to weight loss or due to fatty infiltration attributed to increased hepatic fats evidenced by the observed increase in cholesterol level. Despite
GA dose, route, and treatment duration as well as experimental animal used, our findings are in harmony with Babiker et al. (2017) who showed ALT increase with AST decrease $(p>0.05)$ in healthy rats administered GA (dose of $500 \mathrm{ml} \mathrm{10 \% /5}$ rats/day orally for 12 weeks) indicating GA cytotoxic effect on hepatocytes. Another more recent study of Eyibo et al. (2018) concluded that healthy rats administered GA (at doses of $200 \mathrm{mg} / \mathrm{kg}$ or $400 \mathrm{mg} / \mathrm{kg}$ or $600 \mathrm{mg} / \mathrm{kg}$ orally for 2 weeks) had distorted normal body chemistry reflected in body weight reduction, significant ALT and AST increases, lipid profile alterations, and other biochemical levels. On contrary to our
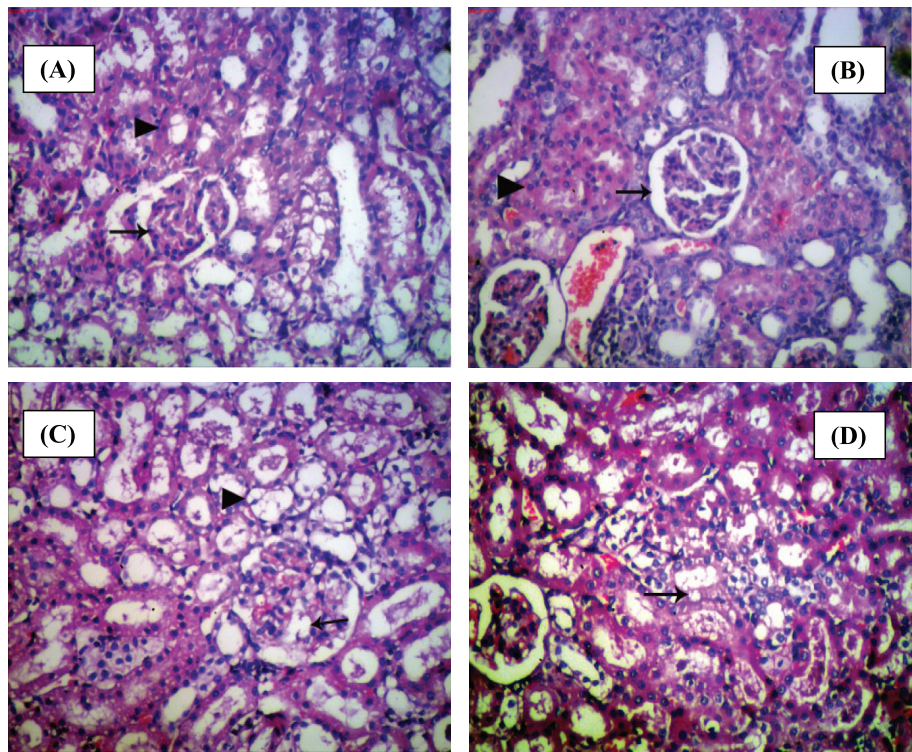

Figure 2. Kidney histo-pathology. Kidney of control rats (A) and kidney of rats administered gum arabic (B) show normal renal glomeruli (arrow) with normal renal tubules lined by normal renal tubular epithelium (arrow head). Kidney of rats injected with adenine (C) shows congestion and necrosis of the renal glomeruli (arrow) with degenerative changes and necrosis of the normal renal tubular epithelium lining renal tubules (arrow head). Kidney of rats injected with adenine in concomitant with gum arabic administration (D) shows normal renal glomeruli with degenerative changes and necrosis of the normal renal tubular epithelium lining renal tubules (arrow) (hematoxylin and eosin, 100×).
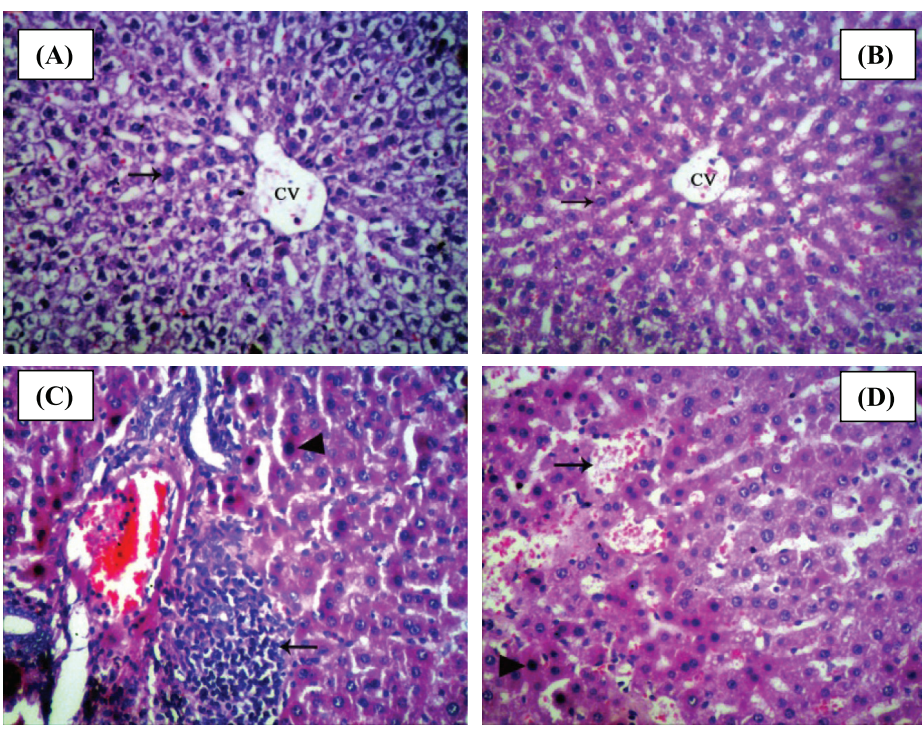

Figure 3. Liver histo-pathology. Liver of control rats (A) and liver of rats administered gum arabic (B) show normal hepatocytes (arrow) and normal radial arrangement around the central vein (CV). Liver of rats injected with adenine (C) shows lympho-histocytic infiltration in hepatic tissue (arrow) and coagulative necrosis of hepatocytes (arrow head). Liver of rats injected with adenine in concomitant with gum arabic administration (D) shows focal hemorrhage in hepatic tissue (arrow) and coagulative necrosis of hepatocytes (arrow head) (hematoxylin and eosin, 100×). 
Table 4. Semi-quantitative analysis of histo-pathological studies on rat kidney and liver in different groups.

\begin{tabular}{|c|c|c|c|c|}
\hline Groups & Control & GA & AD & $\mathbf{G A}+\mathbf{A D}$ \\
\hline \multicolumn{5}{|l|}{ Criteria of kidney } \\
\hline Dilatation of renal tubules & - & - & +++ & ++ \\
\hline Degree of inflammation & - & - & +++ & ++ \\
\hline \multicolumn{5}{|l|}{ Criteria of liver } \\
\hline Necrosis of hepatocytes & - & - & +++ & + \\
\hline Degeneration of hepatocytes & - & - & +++ & ++ \\
\hline Regenerative capacity of hepatocytes & +++ & +++ & - & - \\
\hline
\end{tabular}

results, Gamal el-din et al. (2003) and Alubaidy (2013) observed decreased aminotransferases in mice by GA pretreatment (dose of $100 \mathrm{~g} / 15$ days before acetaminophen hepatotoxic dose) and by GA alone administered to healthy mice (dose of $10 \mathrm{~g} / \mathrm{kg} /$ day orally for 8 days), respectively. No effect of GA (dose of $0.5 \mathrm{~g} / \mathrm{kg}$ orally for 2 months) on liver function tests, including aminotransferases, in healthy rats was recorded by Ayaz et al. (2017).

Incidence of CKD is rising and renal replacement therapy admission by either transplantation or dialysis is limited due to lack of financial and medical resources (Ashuntantang et al., 2017). Entrance of strategies based on dietary supplements seeks to delay the onset of dialysis or to ameliorate uremia (Bellizzi et al., 2016).

Metabolically AD is converted to 2,8-dihydroxyadenine (DHA) which deposits in renal tubules resulting in interstitial inflammation, tubular injure, and fibrosis inducing CKD (Boon et al., 2015). In the present study, kidney patho-histological examination exhibited that the administration of GAalone to normal rats did not cause any harm to renal tissues normal architecture and it confirmed congestion and necrosis of renal glomeruli with necrosis of renal epithelium lining renal tubules induced by AD injection to healthy rats and reflected little amelioration of renal tissues damage by concomitant oral administration of GA with AD. These data indicate that GA can protect kidney tissue against induced CRF to a little extent at the histological level.

Physically, treatment of rats with AD significantly caused a gradual dramatic decrease in rats' body weight. This reduction could be attributed to a reduction in food intake due to uremia (Johari et al., 2008), as a compensatory response increased glycogen, lipid, and protein degradation takes place leading to continued weight loss. Actually, concomitant oral administration of GA with $\mathrm{AD}$ did not normalize rat body weight but it just lowered its reduction from $-25 \%$ to $-3.5 \%$ indicating that GA administration did not significantly alter food intake alternatively it slowed intestinal glucose transport.

On biochemical level and in the same line with (Saad et al., 2018; Nasir, 2013; Poudel et al., 2011), significant elevations of circulated urea, creatinine, BUN, and uric acid in AD treated animals are indicators of impaired kidney function. These data are in consistency with other studies (Ali et al., 2010; Saad, 2013; Saad et al., 2017c; 2017d; Toson et al., 2014). Together with the reductions in body weight, they suggest catabolic prominence existence. GA administration to $\mathrm{AD}$ feeding rats caused significant dramatic reductions in serum concentrations of urea, creatinine, $\mathrm{BUN}$, and uric acid, compared to AD group, to near normal ranges indicating high appreciated improvement in renal function on the biochemical level. These improvements may be attributed to GA ability to reduce the uric acid level and other purine metabolites (Osman et al., 2011), to increase both creatinine clearance and fecal nitrogen excretion, and to induce inhibition of generation of colonic bacterial ammonia (Nasir, 2013), thereby it reduces hepatic urea production rate.

Oxidative stress is the increase in oxidants at the expense of antioxidants resulting in cellular damage (Habib et al., 2015). Commonly, free radicals are scavenged by antioxidants like SOD, catalase, etc., thereby avoiding the oxidative stress (Saad, 2012; Saad and Habib, 2013). Antioxidant effect of GA is still a matter of argument and it has not been resolved; some studies confirmed it and others not (Hamid et al., 2018; Nasir, 2013). Moustafa et al. (2014) observed MDA elevations in GA group (injected once with a dose of $0.2 \mathrm{mg} / 100 \mu \mathrm{l} /$ mice $)(p>0.05)$ and GA plus laser group as well as hepatic hyperplasia groups treated with GA plus laser $(p<0.05)$ compared with control. While Al-Kenanny et al. (2012) observed a significant decrease in MDA in mice with liver injury induced by gentamycin treated with GA (dose of $10 \mathrm{~g}$ / $\mathrm{kg}$ orally for 8 days).

Results of the current study showed that when fed to healthy rats, GA elevates MDA by $40 \%$ and by $20 \%$ in kidney and in liver tissues, respectively. Moreover, it significantly $(p<0.001)$ increases SOD activity by $33 \%$, while it significantly $(p<0.01)$ reduces catalase activity by $10 \%$ in kidney tissues. The situation was reversed in liver tissues as it significantly $(p<0.001)$ reduces SOD activity by $26 \%$, while it significantly $(p<0.001)$ increases catalase activity by $42 \%$. These alterations in antioxidant enzymes (SOD and catalase) may be attributed to renal and hepatic tissues efforts to face oxidative stress. AD injection to healthy rats triggered lipid peroxidation as it caused significant increases in MDA levels either in the kidney or liver. This may be due to precipitation of DHA crystals that could enhance free radicals production such as peroxides and superoxide anion radicals (Veena et al., 2006) resulting in oxidative stress which ultimately causes renal/hepatic cell death. These findings are correlated well with the observed renal and liver histological examination as well as the observed reductions in the activities of antioxidant enzymes SOD and catalase indicating weakened antioxidants scavenging power in AD-induced oxidative stress. Similar results were also observed by others (Ali et al., 2013; Boon et al., 2015). Oral administration of GA to $\mathrm{AD}$ treated rats offered protection against lipid peroxidation and kidney/liver cell damage revealed by decreases in MDA levels associated with increases in antioxidant enzymes activities, which can protect proteins and lipids from 
oxidation by oxidants. This result was in agreement with other studies (Nasir, 2013). The mechanism of this protective effect may be at least in part due to the antioxidant effect of GA.

As far as we know, there is no enough information about GA effect on the liver in renal diseases as very few investigations have been conducted to study this issue. It has long been known that extensive renal damage would also result in hepatic dysfunction due to the interaction of cellular membranes with free radicals mediated by the generation of uremic toxins. Regularly, liver function tests are used to monitor the influences of prospectively hepato-toxic agents or drugs (Saad et al., 2015b; 2017e). Besides, elevated serum cholesterol is considered as a sign for worsening of renal disease (Pandak et al., 1994). In the present study and in agreement with (Boon et al., 2015), animals treated with AD significantly showed $431 \%, 126 \%, 154 \%$, and $45 \%$ increase in total bilirubin, ALT, AST, and cholesterol, respectively, associated with $45 \%$ and $25 \%$ decrease in albumin and total protein, respectively. These results introduce evidence of severe liver injury with cellular infiltration. AST value was greatly higher than that of ALT; this may be due to increased release of mitochondrial AST and AST diminished clearance related to aggressive liver damage (Saad, 2014). Observed total bilirubin increase could be attributed to chronic hemolysis as a result of uremic toxins accumulation in the blood (Yavuz et al., 2005). Reductions in albumin and total protein may be due to impaired synthesis by hepatocytes, as a result of hepatic inflammation and oxidative stress, along with increased protein degradation and renal loss. Elevated cholesterol level may be due to alteration in feedback regulation of 3-hydroxy3-methylglutaryl CoA reductase enzyme (Pandak et al., 1994) as a result of changes in protein synthesis and degradation.

In the present study, concomitant feeding of GA turned levels of liver function tests toward normal but still far from the normal ranges in the control group. Similarly, the results of Al-Kenanny et al. (2012) showed significant decreases in ALT and AST in mice with liver injury induced by gentamycin treated with GA but they did not reach normal levels. These results were parallel with the histo-pathological examination findings. Together, indicate that GA mildly antagonizes hepatic injury following ADinduced CRF. This may be explained on the basis of GA antioxidant effect that protects against cellular leakage and loss of functional integrity of hepatocytes cell membranes. In addition to Babiker et al. (2017) and Eyibo et al. (2018), our results regarding GA effect on liver were in the same line with Moustafa et al. (2014) who observed that GA did not protect or repair hepatocytes deterioration induced by diethylnitrosamine $/ \mathrm{CCl}_{4}$ and did not induce cellular apoptosis. Besides, even liver histology of healthy mice treated with GA alone in Al-Kenanny et al. (2012) study showed many pathological changes in hepatic architecture. On contrary to our findings, Gamal el-din et al. (2003) concluded that pretreatment with GA was able to protect mice against acetaminophen-induced liver damage. Alubaidy (2013) reported GA improved oxidative injure and raised liver regeneration and repair capacity. In addition, Ayaz et al. (2017) showed significant decreases in ALT, AST, ALP, and bilirubin along with increases in albumin and total protein to near normal in rats with liver injury induced by trichloroacetate pretreated with GA indicating hepatoprotective effect against subsequent trichloroacetate hepatotoxicity.

\section{CONCLUSION}

In conclusion, this study clearly revealed GA supplement pronounced ability to ameliorate renal damage induced by $\mathrm{AD}$ in rats. Its amelioration of $\mathrm{AD}$-induced renal toxicity is evident through reductions in levels of urea, BUN, and creatinine, and restored albumin and total protein levels as well as reductions in cholesterol level and oxidative stress. GA, when co-administered to AD feeding rats, reversed levels of routine liver function tests toward normal but their levels still far from the normal ranges in control healthy rats indicating mild antagonistic ability against hepatic injury following ADinduced CRF. On the other hand, GA supplementation to healthy rats elevated ALT and AST activities and cholesterol level indicating harmful effects on the liver. We conclude that GA supplement utilization to treat CKD patients must be done under medical supervision and liver function tests should be monitored during the treatment course. It would be more benefit for such patients to use a hepato-protective supplement in addition to GA supplement for better outcomes.

\section{CONFLICT OF INTEREST}

There are no conflicts of interest.

\section{FUNDING}

Nil.

\section{REFERENCES}

Ali BH, Al-husseni I, Beegam S, Al-shukaili A, Nemmar A, Schierling S, Queisser N, Schupp N. Effect of gum arabic on oxidative stress and inflammation in adenine-induced chronic renal failure in rats. PLoS One, 2013; 8(2):e55242.

Ali BH, Al-Salam S, Al Husseni I, Kayed RR, Al-Masroori N, Al-Harthi T, Al Zaabi M, Nemmar A. Effects of gum arabic in rats with adenine-induced chronic renal failure. Exp Biol Med, 2010; 235(3):373-82.

Al-Kenanny ER, Al-Hayaly LK, Al-Badrany AG. Protective: effect of arabic gum on liver injury experimentally induced by gentamicin in mice. Kufa J Vet Med Sci, 2012; 3(1):174-89.

Alubaidy GF. Study the biochemical effect of gum arabic in liver injury and blood serum of mice induced by gentamicin. Bas J Vet Res, 2013; 12(1):243-52.

Ashuntantang G, Osafo C, Olowu WA, Arogundade F, Niang A, Porter J, Naicker S, Luyckx VA. Outcomes in adults and children with endstage kidney disease requiring dialysis in sub-Saharan Africa: a systematic review. Lancet Glob Heal, 2017; 5(4):e408-17.

Ayaz NO, Ramadan KS, Farid HEA, Alnahdi HS. Protective role and antioxidant activity of arabic gum against trichloroacetate-induced toxicity in liver of male rats. Indian J Anim Res, 2017; 51(2):303-9.

Babiker M, Abbas T, Mohammed MEA. Effect of gum arabic on liver function and antioxidant enzymes of sprague-dawley rats. IOSRJPBS, 2017; 12(2):29-33.

Bellizzi V, Cupisti A, Locatelli F, Bolasco P, Brunori G, Cancarini G, Caria S, De Nicola L, Di Iorio BR, Di Micco L, Fiaccadori E. Lowprotein diets for chronic kidney disease patients: the Italian experience. BMC Nephrol, 2016; 17(1):77.

Boon AC, Lam AK, Gopalan V, Benzie IF, Briskey D, Coombes JS, Fassett RG, Bulmer AC. Endogenously elevated bilirubin modulates kidney function and protects from circulating oxidative stress in a rat model of adenine-induced kidney failure. Sci Rep, 2015; 5:15482.

Dobelis IN (Ed.). Magic and medicine of plants. Reader's Digest Association, Inc, Pleasantville, New York, NY, 1986. 
El-Habibi EM. Renoprotective effects of Punica granatum (pomegranate) against adenine-induced chronic renal failure in male rats. Life Sci J, 2013; 10(4):2059-69.

Eyibo AS, Istifanus G, Blessing OE, Bogolnaan AD, Denkok Y. Determination of the effect of gum arabic on body weight and some biochemical parameters on Albino Wistar Rat. EJNFS, 2018; 8(1):14-9.

Gamal el-din AM, Mostafa AM, Al-Shabanah OA, Al-Bekairi AM, Nagi MN. Protective effect of arabic gum against acetaminopheninduced hepatotoxicity in mice. Pharmacol Res, 2003; 48(6):631-5.

Habib SA, Saad EA, Elsharkawy AA, Attia ZR. Pro-inflammatory adipocytokines, oxidative stress, insulin, $\mathrm{Zn}$ and $\mathrm{Cu}$ : interrelations with obesity in Egyptian nondiabetic obese children and adolescents. Adv Med Sci, 2015; 60(2):179-85.

Hamid M, Abdulrahim Y, Liu D, Qian G, Khan A, Huang K. The hepatoprotective effect of selenium-enriched yeast and gum arabic combination on carbon tetrachloride-induced chronic liver injury in rats. J Food Sci, 2018; 83(2):525-34; doi:10.1111/1750-3841.14030

Johari H, Parhizkar Z, Talebi E. Effects of adenine on the pituitarygonad axis in newborns rats. Pakistan J Biol Sci, 2008; 11(20):2413-17.

Moustafa D, Gamal-Eldeen AM, Saleh S, El-Daly SM. The pharmacological effect of gum arabic on liver hyperplasia in the presence or absence of laser beam. Int J Innov Res Dev, 2014; 3(7):269-73.

Nasir O. Renal and extrarenal effects of gum arabic (Acacia senegal) — what can be learned from animal experiments? Kidney Blood Press Res, 2013; 37(4-5):269-79.

Osman ME, Abu Zeid IM, Adam FA. 2011. Gum arabic: a reducing agent of uric acid and a supportive treatment of gout. In: Kennedy JF, Phillips GO, Williams PA, ed. Gum arabic. UK: RSC Publishing 301-8. doi:10.1039/9781849733106-00301

Pandak WM, Vlahcevic ZR, Heuman DM, Krieg RJ, Hanna JD, Chan JC. Posttranscriptional regulation of 3-hydroxy-3-methylglutaryl coenzyme A reductase and cholesterol 7 alpha-hydroxylase in rats with subtotal nephrectomy. Kidney Int, 1994; 46(2):358-64.

Poudel B, Mittal A, Yadav BK, Sharma P, Jha B, Raut KB Estimation and comparison of serum levels of sodium, potassium, calcium and phosphorus in different stages of chronic kidney disease. Nepal J Epidemiol, 2011; 1(5):160-7.

Saad EA. Curative and protective effects of L-arginine on carbon tetrachloride induced hepatotoxicity in mice. Biochem Biophys Res Commun, 2012; 423(1):147-51.

Saad EA. Kidney response to L-arginine treatment of carbon tetrachloride-induced hepatic injury in mice. Nat Sci, 2013; 5(1):1-6; doi:10.4236/ns.2013.51001

Saad EA. Non-invasive assessment of liver fibrosis using serum markers. J Pharm Chem Biol Sci, 2014; 2(2):59-76.

Saad EA, El-Gayar HA, El-Demerdash RS, Radwan KH. Frankincense administration antagonizes adenine-induced chronic renal failure in rats. Phcog Mag, 2018. doi: 0.4103/pm.pm_271_18 [Ahead of print].

Saad EA, Habib SA, Eltabeey M. Diagnostic performance of AFP, autotoxin and collagen IV and their combinations for non-invasive assessment of hepatic fibrosis staging in liver fibrosis patients associated with chronic HCV. IJPQA, 2017e; 8(4):165-73; doi:10.25258/ijpqa. v8i04.10542
SaadEA, Habib SA, Refai WA, ElfayoumyAA. Malondialdehyde, adiponectin, nitric oxide, $\mathrm{C}$-reactive protein, tumor necrosis factor-alpha and insulin resistance relationships and inter-relationships in type 2 diabetes early stage. Is metformin alone adequate in this stage? Int J Pharm Pharm Sci, 2017a; 9(10):176-81; doi:10.22159/ijpps.2017v9i10.21149

Saad EA, Habib SA. Effect of crude extracts of some medicinal plants on the osmotic stability of human erythrocytes in vitro. J Free Radicals Antioxidants Photon, 2013; 139:265-72.

Saad EA, Hassanien MM, El-Hagrasy MA, Radwan KH. Antidiabetic, hypolipidemic and antioxidant activities and protective effects of Punica granatum peels powder against pancreatic and hepatic tissues injuries in streptozotocin induced IDDM in rats. Int J Pharm Pharm Sci, 2015b; 7(7):397-402.

Saad EA, Hassanien MM, El-lban FW. Nickel(II) diacetyl monoxime-2-pyridyl hydrazone complex can inhibit Ehrlich solid tumor growth in mice: a potential new antitumor drug. Biochem Biophys Res Commun, 2017d; 484(3):579-85.

Saad EA, Hassanien MM, El-mezayen HA, ELmenawy NM. Regression of murine Ehrlich ascites carcinoma using synthesized cobalt complex. Med Chem Commun, 2017c; 8:1103-11; doi:10.1039/ C6MD00618C

Saad EA, Hassanien MM, Elneely EA. Iron(III) diacetylmonoxime-2-hydrazinopyridine complex: a new prospective antitumor drug. Appl Organomet Chem, 2017b; 31(9):e3684; doi:10.1002/ aoc. 3684

Saad EA, Toson EA, Ahmed GM. Clove or green tea administration antagonizes khat hepatotoxicity in rats. Int $\mathrm{J}$ Pharm Pharm Sci, 2015a; 7(6):72-6.

Toson EA, Habib SA, Saad EA, Harraz NH. Toxic and anti-fertility effects of Alocasia macrorrhiza and Calotropis procera ethanolic extracts on male mice. Int J Biochem Photon, 2014; 195:328-38.

Umeukeje EM, Wild MG, Maripuri S, Davidson T, Rutherford M, Abdel-Kader K, Lewis J, Wilkins CH, Cavanaugh K. Black Americans' perspectives of barriers and facilitators of community screening for kidney disease. Clin J Am Soc Nephrol, 2018; 13(4):551-9. doi:10.2215/ CJN.07580717

Veena CK, Josephine A, Preetha SP, Varalakshmi P, Sundarapandiyan R. Renal peroxidative changes mediated by oxalate: the protective role of fucoidan. Life Sci, 2006; 79(19):1789-95.

Yavuz A, Tetta C, Ersoy FF, D'Intini V, Ratanarat R, De Cal M, Bonello M, Bordoni V, Salvatori G, Andrikos E, Yakupoglu G. Uremic toxins: a new focus on an old subject. Semin Dial, 2005; 18(3):203-11.

\section{How to cite this article:}

Saad EA, El-Gayar HA, EL-Demerdash RS, Radwan KH. Hepato-toxic risk of gum arabic during adenine-induced renal toxicity prevention. J App Pharm Sci, 2018; 8(12): 104-111. 